\title{
How to Calculate the Costs of Poverty in Canada: Comment on the Nathan Laurie Approach and Recommended Improvements ${ }^{1}$
}

Charles Plante

Postdoctoral Fellow, Johnson Shoyama Graduate School of Public Policy, University of Saskatchewan.

Phone: +1 306514 0890. Email: charles.plante@usask.ca.

\footnotetext{
${ }^{1}$ The author thanks Alex Paterson, John Stapleton, and Trish Henessy for their helpful comments and suggestions on this work. The author would like to especially thank Iglika Ivanova with whom the author convened at length on how to improve the Laurie approach. This project was funded in part by Upstream, a sub-project of the Canadian Centre for Policy Alternatives. All errors and omissions are the author's own. The author declares that they have no conflict of interest.
}

December 2020 


\title{
How to Calculate the Costs of Poverty in Canada: Comment on the Nathan Laurie Approach and Recommended Improvements
}

\author{
$\underline{\text { Abstract }}$ \\ In 2008, Nathan Laurie calculated the costs of poverty in Canada and Ontario for the first time. \\ Since then, several researchers have used the approach he developed to calculate the costs of \\ poverty for most of the Canadian provinces. This research has had a substantial impact on the \\ thinking of the public and policy makers around poverty and poverty reduction in Canada. In this \\ working paper, we distill the central tenants of Laurie's approach and recommend several \\ improvements that can be made to it. In effect, Laurie's approach works with readily available \\ data to answer the counterfactual question: what would the savings and gains be to individuals \\ and society if we raised the standard of living of the poor to the modest level achieved by the \\ second income quintile or higher? In several places, however, his approach results in estimates of \\ costs that are insensitive to changes in widely recognized measures of poverty, including \\ Canada's new Official Poverty Line, otherwise known as the Market Basket Measure (MBM). \\ In the latter sections of this paper, we reproduce Laurie's original calculations and contrast these \\ with results based on our own recommendations in the same year. Our recommendations \\ generate comparable results.
}

\section{Keywords}

cost of poverty, opportunity cost, public spending, deprivation, social policy, Nathan Laurie 


\section{Introduction}

In 2008, Narthan Laurie estimated the total cost of poverty in Ontario and Canada for the Ontario Association of Food Banks (OAFB). This was the first time this kind of calculation had been done in Canada, although it also built on similar work in the United States and the United Kingdom which estimated the cost of child poverty (Hirsch 2008; Holzer et al. 2008). ${ }^{2}$ In the years since, researchers have adapted Laurie's methodology to calculate the costs of poverty for most of the other provinces and for Ontario, a second time (Lee and Briggs 2019). ${ }^{3}$ These results have been used widely by advocates and policymakers to guide public conversations about poverty and motivate government action to combat it. ${ }^{4}$

In this paper, we summarize the Nathan Laurie approach to calculating the cost of poverty in detail and recommend a handful of improvements that can be made to it. In short, the method is guided by a straightforward thought experiment: what would the savings and gains to individuals and society be if we were to raise the standard of living of the poor in Canada to the modest level achieved by the second income quintile? The approach then supplies answers to this question for three areas of cost: remedial, opportunity, and intergenerational.

The method is less concerned by trying to assign an exact cost to poverty than it is providing a reasonably accessible estimate that convinces readers that poverty has significant costs associated with it. The thought experiment that guides it is chosen, in part, for its intuitive appeal and also its amendability to being explored using information and data that are relatively widely accessible. Laurie is also very sensitive to the risk of exaggerating or overestimating costs ${ }^{5}$ and, at nearly every opportunity, errs on the side of methodological choices that lead to lower estimates. Despite the downward bias this introduces, the method still results in costs that represent as much as 4\% to 5\% of Gross Domestic Product (GDP).

Since 2008, new information and data have become available that can be used to refine, extend, and update Laurie's methodology. In this paper, we propose a handful of methodological refinements meant to overcome some inconsistencies and shortcomings of the original method. We then recalculate Laurie's original estimates for 2007, the year (roughly) ${ }^{6}$ for which Laurie estimated the costs of poverty, and then re-estimate them using the improved methods we propose and newer sources of information. Although 2007 is an old year to centre the presentation in this paper around, it's important to do so in order to draw the clearest contrast between Laurie's original approach and our suggested improvements.

The primary limitations of the original Laurie approach are threefold. First, as a result of data limitations, Laurie sometimes defines the poor as households with incomes below the Low Income Cut-Off (LICO) and other times as households in the first income quintile. Using a

\footnotetext{
${ }^{2}$ McLaughlin and Rank have updated the cost of child poverty estimates for the United States (McLaughlin and Rank 2018).

${ }^{3}$ Specifically, for British Columbia (Ivanova 2011), Alberta (Briggs and Lee 2012), Saskatchewan (Plante and Sharp 2014), Quebec (Barayandema and Frechet 2012), New Brunswick (MacEwen and Saulnier 2011), Prince Edward Island (MacEwen 2011), and Nova Scotia (MacEwen and Saulnier 2010).

${ }^{4}$ For example, cost of poverty calculations were instrumental in motivating the decisions of the governments of both Alberta and Saskatchewan to commit to adopting provincial poverty reduction strategies.

5 "This [study] also deliberately takes a conservative methodological approach in order to ensure that we do not exaggerate or overstate the costs of poverty" (Laurie 2008:7-8).

${ }^{6}$ Laurie actually presents his cost of poverty estimates as though they are for 2008 , however, the data he uses is largely taken from the years 2006 and 2007.
} 
purely relative definition of poverty (i.e., the first income quintile) results in a costing of poverty that is insensitive to changes in more widely recognized and used indicators of poverty, such as Canada's new Official Poverty Line (GoC 2018). Second, the way that the method quantifies intergenerational costs of poverty makes it difficult to use the method over time without double counting. Third, although the method considers how intergenerational poverty dynamics can pass on opportunity costs over the life course, it does not consider how they can also pass on remedial costs. In the concluding sections of this paper, we highlight some promising directions for improving on the Laurie method.

Although the Laurie approach to calculating the costs of poverty in Canada is an imperfect one - even after implementing the changes recommended in this paper - it is still the leading approach Canadian researchers have available and the only one that is widely used. This paper provides a comprehensive exposition of the approach that is sure to be of use to researchers and analysts, whether their objective is to replicate the method, improve on it, or merely better understand it.

\section{The costs of poverty}

Actions to alleviate poverty are often justified on ethical or rights-based grounds. As Holzer et al. (2008) explains, this argument usually stresses the negative effects of poverty on individuals and families, and, especially, children. In rich democratic countries like Canada and the United States, where equal opportunity is widely accepted as a premier goal of public policy, inequities and inequalities that are driven by poverty are troubling. Societal efforts to combat these inequities are often interpreted in terms of charity.

However, poverty also has a wider economic cost that burdens society as a whole and, as such, actions to address poverty can be understood as investments. Calculating this amount can be a useful exercise because moral reasons are not always enough to mobilize public support and incentivize government action. Additionally, this kind of exercise is essential in order to fully appreciate the consequences of inaction. When the costs of poverty are underestimated or entirely disregarded, interventions are more likely to be seen as being too costly or even unrealistic. Too often the costs of inaction or ineffective policy are ignored.

In addition to motivating intervention generally, estimating the costs of poverty can also help us to evaluate different kinds of interventions. Poverty is a multidimensional process that results in costs in many different areas. Interventions of varying scale and cost are likely to be more or less effective at reducing the cost of poverty and various components of it. Contrasting how different interventions can lead to different kinds and levels of reductions in cost can allow us to make more intelligent comparisons among them in terms of their effectiveness and efficiency.

In his approach, Laurie details three general categories of social costs: remedial, opportunity, and intergenerational.

\section{Remedial costs of poverty}

Remedial costs are the direct costs of poverty that, for most people, are the easiest to envisage and understand. In short, poverty can cause people to deteriorate - that is, it damages them. Remedial costs refer to the expenses that are incurred by society in order to repair this damage. In his methodology, Laurie, specifically considers two areas of remedial costs, those associated with health and crime. 
Health costs are related to the degradation that poverty causes people's bodies, physically and mentally. A large and growing body of Canadian research has established income as an important determinant of health (CIHI 2015; PHAC 2018; Plante, Missiuna, and Neudorf 2020). Having too little income makes people more susceptible to illness and associated complications, and less likely to receive the care they need (Lutfey and Freese 2005). Ultimately, these dynamics drive up health system costs (PHAC 2016).

Similarly, poverty leads to dynamics of social exclusion that can make people both more likely to commit crimes of desperation and to become victims of crime (Hsieh and Pugh 1993). Less research has explored the association between income and crime in Canada, although income has been shown to be an important determinant of literacy (Green and Riddell 2007), a more well established predictor of crime. Poverty also isolates people making them more likely to be victimized (Eisler and Schissel 2004; Gaetz 2004). Ultimately, poverty leads Canada to spend billions of dollars on our criminal justice system (Zhang 2010) that we might not otherwise, if poverty could be reduced.

Remedial costs are those costs associated with treating the damage that poverty causes both individuals and communities and need not only include health and crime costs. However, these two areas have received the bulk of the attention in previous Canadian cost calculations.

Opportunity costs of poverty

Insofar as remedial costs are the direct costs of poverty, opportunity costs can be thought of as its indirect costs. The opportunity costs of poverty reflect the achievements that the poor are unable to realize as a result of their being poor. Poverty causes people stress that makes it harder for them to make good economic decisions for themselves and their loved ones (Mani et al. 2013); it also prevents them from taking full advantage of opportunities when they arise (Duflo 2006; Haushofer and Fehr 2014).

The negative effects that poverty has on cognition, health and well-being, access to opportunities, and incentive structures lead the poor to not realize their full potential and, as a result, society as a whole to not realize its full economic potential. This can have a non-negligible impact on one of the primary yardsticks Canadians use to measure their collective achievement: GDP. Although Laurie treats these economic costs as private, this is not the custom in studies that have been conducted in the US and the UK (Hirsch 2008; McLaughlin and Rank 2018). This is because the kinds of economic stimulus caused by increases in productivity tend to advance everyone's economic opportunities.

In reducing GDP, poverty also reduces the amount of tax revenues governments are able to collect. Given that tax revenues are collected with the direct purpose of being re-invested in public goods and socially beneficial programs, the cost of foregone revenues are thus transparently social in nature.

\section{Intergenerational and life course costs of poverty}

Laurie defines the intergenerational costs of poverty as the cumulative long-run costs of poverty that arise because poverty today tends to give rise to poverty tomorrow. Although Laurie focuses exclusively on the intergenerational costs of poverty, that is the way that poverty in childhood tends to lead to poverty in adulthood, the costs of poverty can also accumulate over time within adulthood. Broadly, we can think of intergenerational costs as a subset of life course costs of poverty. 
Life course costs of poverty arise from the interaction between remedial and opportunity costs. Just as people who suffer damage will be less capable of taking advantage of economic opportunities, so too will people that are unable to take advantage of economic opportunities be more susceptible to suffering damage. This interaction inflates the costs of poverty to be greater than the mere combination of remedial and opportunity costs on their own. Intergenerational costs of poverty are relatively easy to gauge because it is relatively easy to demarcate childhood and adulthood.

Laurie only considers the intergenerational costs associated with inflated opportunity costs; that is, how children growing up in poverty today are liable to be less productive and contribute less in taxes later in life than those not growing up in poverty. However, arguably, the cumulative and enduring costs of poverty are also likely to operate in remedial costs.

\section{The cost of poverty}

The total cost of poverty is just the sum of present and life course remedial and opportunity costs in each of the three described categories. In Laurie's 2008 report, he considers two present categories of remedial costs, health and crime, and two present categories of opportunity cost. He then also measures intergenerational life course costs related to the two present areas of opportunity cost he considers. Taken together, then, Laurie considers six areas of costs.

If we also consider the enduring impact of the two areas of remedial costs Laurie considers, then the total cost of poverty $C$ can be understood to be the sum of eight categories of cost:

$$
C=H+M+E+T+H^{\prime}+M^{\prime}+E^{\prime}+T^{\prime}
$$

where $H$ is the health cost of poverty, $M$ is the crime cost of poverty, $T$ is the government revenue cost of poverty, and $E$ is the productivity-related cost of poverty minus $T$. Their associated life course costs are indicated by the same terms with primes.

Laurie also includes the cost of social assistance in his estimates, twice. As we explain below (and in detail in Appendix A), he includes it the first time because he uses after-tax income to measure lost productivity costs. He includes it the second time as a cost similar to remedial costs. ${ }^{7}$ However, arguably, social assistance should be counted in a separate category of costs: investments made to offset the costs of poverty. For this reason, we exclude it from the modified approach we recommend. We discuss this choice at length in the discussion below.

This paper concentrates on how we can estimate the cost of poverty in each of the eight areas listed in Equation 1. This is done in order to draw parallels with Laurie's original methodology and in order to keep things manageable. Of course, Equation 1 is not likely to be exhaustive and we would encourage others to consider additional areas of cost. ${ }^{8}$

\footnotetext{
${ }^{7}$ Barayandema and Fréchet (2012) also categorize social assistance as a remedial cost.

${ }^{8}$ For example, in their updated estimates of the costs of child poverty in the US, McLaughlin and Rank (2018) consider the remedial costs associated with housing the homeless.
} 


\section{Methodology}

\section{The Nathan Laurie approach}

The Nathan Laurie approach estimates the cost of poverty in each area it considers by attempting to answer the question: what would the savings and gains to individuals and society be if we were to raise the standard of living of the poor in Canada to the level of non-poor? In order to avoid overestimating the costs of poverty, in most of his calculations, Laurie uses as his benchmark for the non-poor, the modest standard set by the second income quintile.

In order to help illustrate the benchmark for the non-poor Laurie uses, Table 1 summarizes some of the typical features of non-elderly and elderly households in the second adjusted after-tax income quintile in $2007 .{ }^{9}$ Non-elderly households typically consisted of two parents and a child and earned about $\$ 32,000$ annually. They, nonetheless, ended up living on roughly $\$ 38,000$ annually after taxes and transfers, suggesting that they received more in government transfers than they contributed in taxes. Meanwhile, their elderly counterparts were more likely to be living alone and have few to no children. They lived mostly on government transfers, a combination of pensions and old-age security.

$* * * *$ Table 1. Table summarizing a typical 2nd quintile household in $2007 . * * * *$

In general, the Laurie approach calculates cost $Y$ in a given area (for example, $H, M$, $E$, or $T$ ) using the following equation:

$$
Y=P(\bar{Z}-\bar{X})
$$

where $\bar{Z}$ and $\bar{X}$ are the average costs associated with members of the poor and non-poor, respectively, ${ }^{10}$ and $P$, a scaler, which multiplies the difference $\bar{Z}$ and $\bar{X}$ by the number of households or individuals that are affected.

In effect, Laurie calculates costs in each dimension, by identifying an estimate of the difference in per household costs between the poor and the second income quintile $(\bar{Z}-\bar{X})$ and then multiplying this amount by an estimate of the number of affected poor in the population ( $P$ ). As such, the method is sensitive to changes in how the per household discrepancy in costs is calculated and how many households are identified as poor.

Notably, Laurie does not approach these calculations in the same way for each area of costs of poverty. For instance, when Laurie calculates the remedial costs of poverty, he assumes that all members of society contribute to costs and so $\mathrm{P}$ is simply the number of poor households in society. However, when he calculates the opportunity costs, $P$ is only the number of poor non-elderly households, because elderly households are not expected to earn and contribute to

\footnotetext{
${ }^{9}$ Adjusted after-tax income here refers to total household income divided by the square root of household size and weighted by population. This adjustment is widely used in poverty studies to make incomes more comparable among households that are different sizes (Murphy, Zhang, and Dion 2010).

${ }^{10}$ When the outcomes are expenses, as in the case of health care or justice system costs, their averages take on negative values and when they are beneficial outcomes, as in the case of wages and salaries, they take on positive values. This results in Equation 2 always having a positive value.
} 
the economy in the same way. Similarly, when Laurie calculates the intergenerational costs of poverty, he uses for $P$ the number of children today that will grow up to be poor.

Articulating Laurie's general approach in Equation 2 provides us with a tool for relating the different methodological choices Laurie makes for calculating costs in each area. It can also help to clarify where improvements to the method can be made.

\section{The second quintile benchmark}

As mentioned, in most of his calculations, Laurie uses the second income quintile as his benchmark for the non-poor. He does this first and foremost in order to ensure that he does not overstate the effects of poverty. Theoretically, the non-poor are likely to be better off but not necessarily only because they are not poor. Once people are non-poor they are likely to be able to accumulate resources that will raise their standard of living further above the poverty line. Comparing the poor to all non-poor risks inflating the differences between the poor and non-poor.

However, there is also a practical reason for using the second quintile as a benchmark and not some other income grouping. Although household-level income data is relatively widely available to Canadian researchers, linked health and crime data are not. More often than not, research on relationships between income and other outcomes is advanced using administrative data that has been linked with income data at the neighbourhood-level, oftentimes grouped by quintile or decile data. For example, the Mustard et al. (1998) study that is pivotal to Laurie's remedial health calculations determines the different shares of total health spending that are allocated to deciles. Laurie is constrained to work with the income groupings that are available to him.

However, there is an exception to Laurie's use of the second income quintile as his benchmark for $\bar{X}$. When he calculates the intergenerational cost of poverty, he contrasts average costs associated with the poor with costs associated with the average of all four other income quintiles. This comparison is appropriate because for intergenerational costs the damage of poverty is not only that it keeps children poor, but also that it ensures they fail to ever realize their maximum potential. ${ }^{11}$ This approach is supported by work by Alexander Bell, Raj Chetty, and others (2017) on so-called "lost Einsteins." This research has found that the single most important predictor of the achievements of inventors in the United States is having rich parents. Poverty in childhood does not only prevent people from growing up to be non-poor adults but also from being anything more.

\section{Counting the poor}

As mentioned, Laurie does not use a consistent definition of poverty throughout his calculations due to data limitations. ${ }^{12}$ When Laurie uses an explicit and widely recognized measure of poverty, he uses the Low Income Cut-Off (LICO). When he does not, he turns to the extremely unorthodox measure of the bottom fifth of the population. By this definition, $20 \%$ of the population is always poor, no matter what happens to incomes within the population.

\footnotetext{
${ }^{11}$ As mentioned, these life course costs are also likely to continue to arise during adulthood. Laurie excludes life course costs during adulthood and, in doing so, errs on the side of underestimating life course costs overall.

12 "Although we use Statistics Canada's low-income cutoffs (LICOs) in a few instances, for the most part we classify people living in poverty as those in the lowest income quintile; that is, the 20 percent of people who have the lowest incomes" (8).
} 
Figure 1 illustrates poverty trends since 2006 using the LICO, and two other widely recognized measures of poverty, the Market Basket Measure (MBM) — also Canada's new Official Poverty Line (GoC 2018) — and the Low Income Measure (LIM) (Statistics Canada 2016) — otherwise known as the "relative poverty measure" (Brady 2003). Evidently, Laurie's one-fifth threshold defines a far greater share of the population as poor than the other measures and it does not change over time. In contrast, the other measures result in poverty levels that change regularly.

\section{****Figure 1. Poverty trend over time, quintile, MBM, and LIM.****}

Theoretically, our cost of poverty estimates should be sensitive to changes in the level of poverty. ${ }^{13}$ Holding the level of poverty constant — as does Laurie's one-fifth threshold — is problematic. Given the recent Government of Canada decision to select the MBM as Canada's official poverty line, it would make sense, wherever possible, four our cost of poverty estimates to be sensitive to this measure in particular.

Laurie's choice of poverty measure further affects his cost estimates in each of two ways. First, by determining the group over which he estimates $\bar{Z}$, that is, the group that he identifies as poor and that he will compare with the non-poor. Second, by determining the size of the scaler $P$, or the number of poor by which he multiplies this discrepancy to arrive at his estimate of the overall cost of poverty in each area.

Laurie is particularly inconsistent in how he defines poverty in the process of calculating $\bar{Z}$, selecting a different population (and/or combination thereof) for calculations in each cost category. For his remedial calculations, he calculates the difference between $\bar{Z}$ and $\bar{X}$ as the difference in the average outcomes between the first and second income quintile. For his opportunity cost estimates he uses two different estimates of $\bar{Z}$, the average outcome within the first quintile and the average outcome among those households deemed poor by the LICO. For his intergenerational calculations, he only uses the latter.

Though Laurie varies the group over which he defines $\bar{Z}$ between his remedial and opportunity calculations, he is more consistent in his definition of $P$. For both remedial and opportunity costs, $P$ is defined over households in the lowest quintile, however, as mentioned above, he excludes elderly households for the latter calculation. For his intergenerational concept, Laurie turns to the LICO, defining $P$ as a function of the number of children living in poverty by that measure. He does not consider the number of children living in the lower income quintile.

Some of these choices are more problematic than others. In the following sections, we work systematically through how Laurie calculates poverty in each area and make a handful of recommendations for how they can be made to be more consistent.

\section{Calculating costs using Canadian data}

In order to calculate the costs of poverty in each of the six dimensions he considers, Laurie makes several methodological choices. In the following sections we present in detail how Laurie calculates costs in each area and consider some of the limitations of the choices he makes. We

\footnotetext{
${ }^{13}$ This having been said, following on from Equation 2, if the differential in costs between the poor and second income quintiles are reduced to zero, then cost estimates will be zero and unaffected by how many poor there are.
} 
will also make recommendations regarding how they can be improved. In some cases, this just means updating the information used to make the calculations; in others, it means modifying how they are actually calculated.

Before we begin detailing each method, however, it can help to briefly consider the results generated by the approach as a whole. In order to ensure we fully understood Laurie's approach, we reproduced his exact estimates using the information and sources he provided in his original report. The results of these calculations are presented in Table 2. (The only discrepancies that arise are in the upper estimate of the cost of lost government revenue and both lower and upper estimates of the same in intergenerational costs. These differences appear to reflect errors in Laurie's calculations as the surrounding estimates that used the same methods are identical.) Implicit values, those articulated in Equation 2, are also presented.

In general, productivity costs play an outsized role in Laurie's calculations. Similarly, present costs have a greater impact than those that arise over the life course through intergenerational processes. Laurie estimates the total cost of poverty to be in the range of $\$ 72.1$ to $\$ 82.6$. In 2007 , this amounted to roughly $4 \%$ to $5 \%$ of GDP.

****Table 2. Laurie's overall results compared to our proposed overall results****

\section{Health costs}

In order to calculate the health costs of poverty, Laurie does not actually directly calculate $P, \bar{Z}$ , and $\bar{X}$. Rather, he combines estimates by Mustard et al. (1998) of the share of total health care expenses that are spent on the bottom and top income quintiles with current total expenditures to estimate how much is spent on each quintile. In effect, he makes the following calculation:

$$
Y=P \bar{Z}-P \bar{X}
$$

where $P \bar{X}$ is equal to the total cost associated with the second income quintile, $P \bar{Z}$ the total cost associated with the first, and $P$ is implicitly assumed to be one-fifth of the population.

Mustard et al. (1998) estimated the distribution of health care expenses by income quintile expenditures in Manitoba in the late 1980s and early 1990s. Mustard et al. calculated their estimates by linking Manitoba Health Services administrative data on publicly insured physician services, acute care hospital services, and institutional long term care services and their costs with household income data collected in the 1986 Census.

Laurie calculates the health costs of poverty for Canada and Ontario in 2007 by multiplying the quintile shares estimated by Mustard et al. by the system-wide amounts of health care expenditure tabulated annually by the Canadian Institute for Health Information (CIHI) (2018a). CIHI tabulates these numbers for Canada as a whole and each of the provinces for each year going back to the 1970s. After Laurie, researchers have worked with CIHI and Mustard et al.'s numbers to calculate health costs for other provinces.

Of course, the distribution of health care expenses by income that Mustard et al. estimate is highly specific - Manitoba in the late 1980s - and somewhat outdated. More recently, the Public Health Agency of Canada (PHAC) (2016) has worked with similar data (although including prescription medication costs and excluding long term care costs) for the country as a 
whole in the year 2008. In the absence of studies that have calculated similar estimates in a systematic and comparable fashion at lower levels of geography, we recommend updating calculations to use the PHAC shares.

****Table 3. Mustard and PHAC's health spending shares.****

Table 3 contrasts Mustard et al.'s Manitoba estimates of the share of health care expenditures for Manitoba in the late 1980s with PHAC's more recent national-level estimates. The difference between the first and second income quintile shares in Mustard et al.'s estimates is 0.67 , however, the difference in the PHAC estimates is somewhat less at 0.57 . This could reflect decreases in health inequalities in Canada over time, but it could also simply reflect greater health inequalities in Manitoba or in the past. It could also partially reflect the fact the Mustard et al.'s estimates do not appear to be standardized for age but PHAC's are.

CIHI continues to release regular estimates of health expenditures annually. Table 4 displays the components of public health expenditures in Canada and their relative contribution. These expenditure estimates are fairly expansive and include everything from investments in physician visits and acute care, to prescription drugs, and on to services that are often regarded as optional and not routinely covered by public health care like eye and dental care (CIHI 2018b). However, health costs for which health goods or services are not sought will also not be covered.

****Table 4. Components of health costs (CIHI Figure 10)****

Finally, it is worth considering whether reweighting health costs by the number of households that fall below the poverty line is worthwhile. Although Laurie says that he leans on the bottom fifth definition of poverty due to data constraints, this restriction is not necessary. ${ }^{14}$ The limits of administrative data described above only affect our ability to estimate $\bar{Z}$ and $\bar{X}$. As long as we know $P$, we can substitute it for any other value by inferring $\bar{Z}$ and $\bar{X}$ and multiplying it by another scaler. (We return to the matter of what this scaler should be in the discussion below.) For instance, in Table 2 we present the implicit values of $\bar{Z}$ and $\bar{X}$ used in Laurie's calculatations. In 2007, there were 2,630,100 households in each quintile, including elderly households. Dividing $P \bar{Z}$ and $P \bar{X}$ by this amount leaves us with $\bar{Z}$ and $\bar{X}$.

\section{Crime costs}

As is the case with his health calculations, in order to calculate income quintile specific costs, Laurie begins by determining the amount of the outcome that is associated with each quintile, then multiplies these by the total estimated costs. However, for his crime calculations, Laurie was not able to draw on ready made estimates of quintile specific expenditure shares and total expenditures. Instead, in each case, he has to cobble them together from multiple sources.

Laurie works with two pieces of information to determine the share of crime associated with each income quintile. Laurie begins by noting that education and literacy have been widely

\footnotetext{
${ }^{14}$ Laurie's remedial estimates can be adjusted to account for any given number of poor. All that is needed is to divide the difference in total costs associated with each quintile by one-fifth of the population (note that this works because the number of people in the first and second quintiles is the same). This results in a per household estimate of cost that can be multiplied by any $P$. Since this estimate contrasts costs in the first and second quintiles it tends to err on the side of underestimating costs because the first quintile usually includes some non-poor.
} 
found to be important determinants of crime. In the absence of data that looks directly at the relationship between crime and income in Canada, the first piece of information that Laurie turns to is a table he locates in a study by Green and Riddell (2007) which offers estimates of the joint distribution of literacy quintiles and income quintiles for Canada as a whole based on the 2003 International Adult Literacy and Skills Survey (IALSS).

The second piece of information that Laurie draws on is a table that he creates himself based on the relationship that he assumes exists between literacy and the probability of engaging in crime. Although, the two outcomes are widely recognized to be related (Gannon et al. 2005), ${ }^{15}$ exact estimates of their relationship in Canada are not available. In order to make up for this gap, Laurie assumes that a person's probability of engaging in crime will be reduced by half as a person moves from lower to higher literacy quintiles. Barayandema and Fréchet (2012:10) explicitly provide the resulting distribution and we reproduce this in Table 5b.

To arrive at an estimate of the distribution of the probability of engaging in crime conditional on income, Laurie converts Green and Riddell's joint probabilities of literacy and income quintile to conditional probabilities (provided in Table 5a) and multiplies these by his assumed distribution of the probability of engaging in crime conditional on literacy quintile and sums them. The final shares are presented in the rightmost column of Table 5c.

Laurie turns to three sources of information to estimate the total cost of crime in Canada and Ontario in 2007. First, estimates of the total national costs of the criminal justice system, including police services, courts, legal aid, correctional services for adults and judicial proceedings in the 2002-2003 fiscal year, adjusted for inflation (Taylor-Butts 2002). Second, estimates of the costs to victims in 1999, adjusted for inflation (Leung 2004). Third, in order to calculate an Ontario-specific total costs in 2007, Laurie multiplies national total costs by Ontario's share of reported crimes in that year.

****Table 5. How Laurie's crime by income shares are calculated.****

Today, Green and Ridell's research on the relationship between literacy and income has yet to be updated and the relationship that Laurie assumes between literacy and the probability of engaging in crime has yet to be verified. For these reasons, researchers have so far continued to work with Laurie's shares in order to calculate the crime costs of poverty.

The estimated total cost of crime in Canada was updated in 2010 for the year 2008 (Zhang 2010). Unlike the earlier Leung study, which focused exclusively on victim and property related costs of crime, Zhang's 2010 study combines this information with information on justice spending and estimates of intangible costs (presented in Table 6). He estimates that the total cost of crime in 2008 was $\$ 99,575$ billion, $\$ 68,155$ of which are intangible. However, these numbers include estimates of health and productivity related costs that are counted in other areas of our cost calculations. Subtracting these, leaves us with a total cost of \$91,398 billion in 2008 .

****Table 6. Components of Zhang's total crime costs. ****

\footnotetext{
${ }^{15}$ Laurie actually cites Gannon et al. (2005) on this and Gannon et al. cite others, specifically studies from the UK that are difficult to locate. A study by Muirhead and Rhodes (1998) found that as much as $65 \%$ of federal inmate population in the 1990 s was functionally illiterate.
} 
Ideally, our cost of crime calculations could be more sensitive to regional variations in public spending on the justice system. At the time of this writing, Statistics Canada does not report disaggregated estimates of consolidated government expenditures for the category of "703 - Public order and safety," although this is expected to change in the future (Statistics Canada 2014:18). This prevents us from isolating crime related costs within overall spending on public safety. ${ }^{16}$ Meanwhile, tangible and intangible costs of crime would be similarly sensitive to variation in the kinds of crimes committed over time and place. This would require considerable work, although it may be feasible to do so by working with official crime statistics.

As is the case with health expenditures, the total costs is likely to be underestimated because not every cost of crime results in the purchase of quantifiable goods and services. A more pronounced problem for these estimates is that crime statistics tend to be underreported. It is worth noting further that this approach links crime to poverty by arguing that experiencing poverty can lead people to commit crimes that are costly to society. In addition to being more likely to be prosecuted for committing certain crimes, the poor are also far more likely to be the victims of crime (Taylor-Butts 2009).

As is the case with health costs, we should consider reweighting crime costs to reflect the number of poor in the population according to a more exact measure of poverty than the one fifth of the population used by Laurie.

\section{Lost productivity costs}

Laurie estimates lower and upper bounds for his opportunity cost of poverty by calculating his estimate of cost among the poor using two different definitions of poverty. Unlike in the case of remedial costs above, Laurie is able to work with microdata to calculate specific outcomes for households that can be identified as poor. In Table 7, we reproduce the income and tax related quantile estimates that Laurie uses to calculate his opportunity costs. The differences that define the upper and lower bounds of his estimates are included in the bottom two rows.

For his lower estimate, $\$ 18,389$, Laurie contrasts average after-tax income among households in the first income quintile and those in the second, and multiplies this by the number of households in the first income quintile. This approach is consistent with the approach he takes to remedial costs. For his upper estimate, $\$ 21,154$, Laurie performs the same operation but, this time, contrasts the difference in average after-tax income between households living under the poverty line according to the LICO and those in the second income quintile. Since by definition people living in poverty in Canada tend to be a relatively disadvantaged subset of the first quintile, the difference between the second quintile and the poor will always tend to be greater.

Recast in terms of elements presented in Equation 2, Laurie holds $P$ and $\bar{X}$ constant for his lower and upper estimates of lost productivity, but varies $\bar{Z}$. In both, $P$ is the number of households in the first income quintile and $\bar{X}$ is the average household after-tax income of individuals in the second quintile. However, for the lower estimate, Laurie sets $\bar{X}$ to be the average after-tax income of the first quintile, and for the upper estimate, he sets it to be the average after-tax income of individuals living below the poverty line.

At this stage, Laurie also considers the role of social assistance in mediating these costs. Since after-tax income includes social assistance payments, he counts this as a social cost. Since

\footnotetext{
${ }^{16}$ For example, the category contains fire protection services, civil court costs, and R\&D public order and safety (IMF 2001:83-85). Arguably, these should be excluded.
} 
these are also usually clawed back, in order for low income individuals to make up the difference between their income levels and others, they have to earn the difference plus the social assistance. In order to account for this, Laurie counts the social assistance cost a second time.

We would argue that Laurie's approach to calculating the opportunity cost of poverty associated with lost productivity is needlessly complicated (see Appendix A for more detail on this point and why Laurie double counts social assistance). First, it introduces a new method for calculating per household costs that is inconsistent with the available methods for doing so in other dimensions. Second, and perhaps most problematically, it measures lost productivity by contrasting outcomes in after-tax income even though it is not a direct measure of productivity. This is what forces Laurie to also have to work with social assistance in a way that leads him to have to count it twice.

We can avoid these issues if we instead contrast outcomes in earned income-an explicit indicator of labour productivity. Average household earnings within income quintiles can be calculated annually and at various levels of aggregation using Statistics Canada's Public Use Microdata File (PUMF) versions of the Canadian Income Survey (and, in the past, the Survey of Labour and Income Dynamics (SLID)).${ }^{17}$ Working with individual earnings also obviates the need to double count social assistance.

Table 7 contrasts the quintile estimates used by Laurie with those estimated by us. Our estimates are constructed using quintile groupings that have been defined over the entire population (including elderly households) in household adjusted after-tax income. ${ }^{18}$ Given our focus on opportunity costs, however, the averages we calculate are restricted to non-elderly households within those quintiles. ${ }^{19}$ When we look at earnings explicitly as we have constructed it, the difference between the poorer groups and the second quintile is a bit larger. In the case of the difference between the first and second quintile, it increases from $\$ 18,389$ to $\$ 20,983$.

****Table 7. Laurie and our after-tax, earnings, and taxes paid calculations.****

Finally, our opportunity cost calculations should ideally parallel our calculations in other areas. This suggests that we consider not calculating estimates based on two definitions of $\bar{Z}$. Rather than generate lower and upper estimates by changing $\bar{Z}$, we should consider doing so by changing $P$. More on this point below.

\section{Lost government revenue}

Laurie calculates the extent of lost government revenue caused by poverty in the same manner as he does lost productivity, only instead of comparing average levels of household after-tax

\footnotetext{
${ }^{17}$ The PUMF-SLID excludes the Canadian territories, institutionalized populations, persons living on military bases, and those living on reserves. The survey is also administered by phone and is not likely to be administered to the homeless. The CIS has been expanded to include the territories in recent years.

${ }^{18}$ Laurie is vague about how he conceptualizes and operationalizes income quintiles and appears to use different definitions (and years) estimated over populations with and without elderly households throughout his calculations. These inconsistencies are inflamed by the fact that researchers whose estimates of shares we rely on to calculate remedial costs tend to use different definitions of quintiles. That is, Green and Riddell (2007) use pre-tax and transfer income and PHAC (2016) use adjusted after-tax income, at the individual level when possible and otherwise at the area level. Mustard et al. (1998) and Corak (2017) use total income, that is pre-tax income plus transfers - but before taxes - for his mobility calculations.

${ }^{19}$ Defined as households with no adult members less than 65 years of age.
} 
income between the poor and the second income quintiles, he compares the average amount of taxes paid. This approach is more reasonable than that used to calculate lost productivity because it measures exactly what it aims to comment on.

In Table 7, we see that Laurie's estimates of taxes paid are quite a bit larger than those that we estimate directly using the PUMF-SLID 2007. The reason for this discrepancy is that Laurie infers average taxes paid from the difference between average before-tax income and after-tax income (i.e. the difference between those two columns in Table 7). The trouble with this approach is that it glosses over the fact that transfers are also part and parcel of the difference between those incomes. This may work itself out if we include the adjustments for social assistance Laurie makes (see Appendix A) but is also a very convoluted way of accounting for something that can be directly measured.

Accounting for taxes paid cannot be done in exactly the same manner as is done by Laurie if we measure lost productivity by contrasting differences in earnings. This is because taxes are largely paid from monies earned. Lost government revenue, then, is a fraction of overall lost productivity costs (see Appendix A). As such, calculating the two separately then adding them up as Laurie does would result in us counting lost government revenue twice, first as part of the overall discrepancy in earnings, then again on its own.

One way around this issue is to treat lost productivity and lost government revenue as analytically distinct private and social costs that cannot be combined. Another, more appealing approach, is simply to subtract lost government revenue from lost productivity when it is desirable to present the two side by side as private and social costs. Another option is to just focus on lost productivity and ignore lost taxes.

\section{Intergenerational costs}

Laurie calculates intergenerational costs in a similar way as he does opportunity costs, but with three key changes. First, as explained above, rather than contrast the average after-tax income levels and taxes paid by the poor with the second income quintile, he contrasts them with the average of all four upper quintiles. Second, he only considers the discrepancy in costs between households defined as poor by the LICO and the second income quintile. Third, he multiplies this difference by the number of children in poverty that we should expect to grow up to be poor.

In order to determine the number of children that we should expect to grow up to be poor, Laurie looks to research by Fortin and Lefebvre (1998) which finds that roughly $20 \%$ to $25 \%$ of children that grow up in poverty will continue to live in poverty as adults. Multiplying these two amounts by the number of children identified as poor by the LICO in 2007, 760,000, he arrives at lower and upper values he can use for $P$. Multiplying the difference in average after-tax income and taxes paid between households classified as poor by the LICO and the average of the top four quintiles provides him with his lower and upper estimates of the cost of intergenerational poverty in each of the areas of opportunity costs considered above.

For his intergenerational calculations, Laurie contrasts average after-tax income and taxes paid by households in the top four income quintiles with those of households living below the poverty line defined by the LICO. As above, it makes little sense to adopt a comparison that cannot be applied in the same way across all other dimensions using available data. For this reason, the comparisons should be made instead with the outcomes of the bottom income quintile. 
However, this approach remains problematic, even if we compare quintiles as we do for other cost areas, because of how discrepancies will add up over time. Specifically, the difference between the first and second income quintile is already used to count opportunity costs in the present. This is less of an issue if we only wish to calculate the costs of poverty at one point in time but results in double counting if we plan to update our numbers many times into the future.

One way to avoid this conflict is to concentrate instead on differences between discrepancies between the first and second income quintile and the first and the four upper quintiles. Casting this difference in discrepancies in mathematical terms, we have:

$$
\bar{Z}-\bar{V}-(\bar{Z}-\bar{X})=\bar{Z}-\bar{V}-\bar{Z}+\bar{X}=\bar{X}-\bar{V}
$$

where $\bar{Z}$ and $\bar{X}$ are the average costs associated with members of the first income quintile and the second (using the notation introduced above), and $\bar{V}$ is the average cost associated with members of the second through fifth quintiles.

Multiplying $\bar{X}-\bar{V}$ by the number of poor children we expect to grow up to be poor, for example, 152,000 to 190,000 in Laurie's calculations, provides us with a general approach to calculating intergenerational costs:

$$
Y^{\prime}=P(\bar{V}-\bar{X})
$$

where $Y^{\prime}$ is an intergenerational cost in a given dimension (for example, $H^{\prime}, M^{\prime}, E^{\prime}$, or $T^{\prime}$ ).

Although Laurie only calculates intergenerational costs for lost productivity and government revenue, there is little reason to stop at these. We have all the components that we need to be able to calculate the same per household discrepancies that we estimate for opportunity costs for both of our remedial costs - specifically, estimates of total societal cost and of the share of that cost that can be attributed to each income quintile (presented in Tables 3 and $5 c)$.

Turning now to the number of children that we can expect to grow up to be poor, estimates are now available that are more specific than the $20 \%$ to $25 \%$ that Laurie was able to work with. Working with Canadian Census and taxfiler data on parents and children in the late 1960s and early 2000s data, Myles Corak (2017) estimates that no less than $30 \%$ of children that resided in the bottom income quintile between 1963 and 1970 continue to reside in this quintile in adulthood. The reason this number is higher than Laurie's previous estimates is because Corak's estimate is able to isolate mobility rates at the bottom of the income distribution. ${ }^{20}$

****Table 8 . Intergenerational income mobility estimates from Corak (2017)****

A final note of caution, whereas for costs in other dimensions we have multiplied household-level discrepancies by numbers of households, for intergenerational costs we are multiplying them by a number of individual children. As such, this is one dimension in which we

\footnotetext{
${ }^{20}$ Mobility takes a long time to measure. There are reasons to think that mobility will actually be lower for today's children than it was for children in the 1960s (Corak 2013); as such, 0.3 is likely a conservative estimate.
} 
are likely to overestimate these costs to some extent, since some poor children that grow up to be poor will marry each other (Hou and Myles 2008).

\section{Lower and upper bounds}

The primary limitation of Laurie's approach to calculating the cost of poverty is that in several places he operationalizes poverty as residing in a household in the first income quintile, "...for the most part we classify people living in poverty as those in the lowest income quintile; that is, the 20 percent of people who have the lowest incomes" (8). Though this conceptualization accommodates the data he has to work with, it is largely out of sync with leading measures and simultaneously overestimates and underestimates the costs of poverty.

Measures of poverty that are in wide use in Canada ordinarily identify far less than the entire bottom fifth of households as living in poverty. For example, according to the MBM and LIM, respectively, $11 \%$ and $16 \%$ of households lived in poverty in $2007 .{ }^{21}$ Using the bottom quintile to stand in for the number of poor, then, tends to overcount the poor and biases our costs of poverty calculations upward. Laurie uses one-fifth of the population to determine the multiplier $P$ for both his remedial and opportunity cost calculations. Only for his opportunity and intergenerational costs, does he use the number of poor defined by a recognized poverty measure.

At the same time, conceptualizing poverty as a fifth of society also tends to bias our costs of poverty downward. This is because the inclusion of non-poor households dilutes our estimates of average outcomes among the poor $(\bar{Z})$. For his opportunity cost and intergenerational cost calculations, Laurie considers both the differences between the first and second quintile and the poor according to the LICO and the second quintile for precisely this reason. However, this kind of comparison is not possible for his remedial estimates, which rely on other data sources.

In order to illustrate these trade-offs, Table 9 presents estimates of costs associated with lost production and foregone government revenue based on different combinations of using Laurie's quintile definition of poverty and the MBM to define the number of poor $P$, and/or the average cost associated with the poor $\bar{Z}$. It is clear from these tabulations that Laurie's definition has the greatest impact on costs via $P$ (although, this discrepancy will be less insofar as household poverty rates increase toward 20\%). Its impact on estimated total costs via $\bar{Z}$ is relatively modest. These amounts are also illustrated in Figure 2.

\section{****Table 9. Trade-offs in using first quintile definition and MBM**** \\ $* * * *$ Figure 2. Graphing the values in Table $9 * * * *$}

For his remedial cost calculations, Laurie only works with the third combination in Table 9, in which both $P$ and $\bar{Z}$ are calculated based on the number and costs of the first quintile. However, for his opportunity cost calculations, Laurie calculates a lower and upper range by contrasting this third combination with the fourth, which calculates $P$ based on the quintile definition and $\bar{Z}$ based on the poverty measure. As evidenced in Figure 2, both his lower and upper bound cluster toward the top range of the resulting estimates.

\footnotetext{
${ }^{21}$ The LIM is a household level measure of poverty. For these calculations, households were coded as poor by the MBM if they contained at least one poor economic family.
} 
The result that is most consistent with leading definitions of poverty is the one that combines $P$ and $\bar{Z}$ that are calculated based on a widely recognized definition of poverty, such as the MBM. In Figure 2, this result falls well outside of the margin of error of those estimates that were calculated using Laurie's preferred combinations.

Ideally, the combinations we use do not change from one cost category to another. As explained above, because of limitations that are inherent to the kinds of information we have to work with to calculate remedial costs, we cannot actually use combinations that include values of $\bar{Z}$ calculated over poor populations defined by measures like the MBM. If we wish to use the same combinations for all our estimates, then we should use the first and third combinations in Table 9. That is, combinations that use quintiles to estimate discrepancies between the poor and non-poor.

As evidenced in Figure 2, working with the first and third combinations in Table 9 results in us adopting the lower of each clustered estimate of productivity costs. This selection criteria, then, is consistent with Laurie's objective of identifying a conservative approach. It can also be extended to intergenerational costs by working with the number of children living in poverty according to our poverty measure (as Laurie does) to calculate a lower bound and the number of children living in the lower quintile to calculate an upward bound.

However, the greatest strength of this approach is its flexibility. There is considerable disagreement among advocates and researchers as to how poverty should be measured. For example, Laurie's preferred measure, the LICO, has largely fallen out of favour in recent years (Hunter and Miazdyck 2006). In fact, researchers calculating the costs of poverty after Laurie have tended to use the MBM instead (for example, Plante and Sharp 2014). Meanwhile, the LIM is another poverty measure in wide use in Canada and abroad (Murphy, Zhang, and Dionne 2012). Figure 3 illustrates the distribution of resulting costs estimates based on different combinations of quintile and poverty measure if the LIM is used. Evidently, using the LIM raises the lower threshold on cost. This is because the share of households that are poor according to the LIM in 2007 is closer to 20\% than the share according to the MBM (more on this below).

****Figure 3. Graphing the values in Table 9 using LIM****

Using the first and third combinations in Table 9 allows us to estimate the costs of poverty in a manner that is consistent across categories while also being sensitive to leading measures of poverty. If we are confident in our choice of poverty measure, we may also elect to only use the estimate of costs that uses it and ignore the upper bound generated by the quintile definition of poverty.

\section{Summary of changes and their consequences}

Table 10 presents three sets of estimates of the cost of poverty in 2007 that integrate the various recommendations that we make throughout this paper. All three sets of estimates are calculated using the difference in per person costs associated with the first and second income quintiles as we define them above. The difference between the estimates is that we vary $P$, first calculating it as the number of poor by the MBM, second, as the number of poor by the LIM, and third, Laurie's one-fifth poverty measure.

****Table 9. Upper and lower bound estimates based on MBM and LIM**** 
Evidently, our updated calculations result in estimates that are a bit lower than Laurie's, although the upper bounds we settle on are comparable. Whereas Laurie calculates the total cost of poverty in 2007 to range between $\$ 63.9$ and $\$ 74.4$ billion (less the $\$ 8.4$ billion he includes to account for social assistance costs), we calculate them to range between $\$ 46.9$ and $\$ 71.8$ billion. The major differences between our overall estimates arise in the lower bounds of our estimates. This is almost entirely the result of the impact that weighting our calculations by the MBM has on productivity costs. Our productivity cost estimates range from $\$ 44.5$ billion, which is comparable to Laurie's upper estimate of $\$ 41.2$ billion, to as low as $\$ 30.4$ billion. This $\$ 14.1$ billion spread accounts for more than four-fifths of the difference in our lower estimates. Our estimates of remedial and intergenerational costs actually tend to be greater than Laurie's. ${ }^{22}$

The major discrepancies between our estimates and Laurie's are the result of the MBM identifying far less than one fifth of households as poor. In contrast, the LIM identifies $16 \%$ of households as poor, resulting in estimates that fall far nearer to the range of costs estimated by Laurie. When we carry out all of the same calculations using this measure of poverty to calculate $P$, overall cost estimates fall near to Laurie's lower estimate.

The primary shortcoming of this new approach is that it calculates the average per person difference in costs between the poor and non-poor based on the status of people in the first and second income quintiles. At worst, this concession ensures that cost estimates are conservative in a consistent fashion. At best, researchers could improve upon the method by calculating average outcomes according to specific definitions of poverty like the MBM and LIM.

Regardless, for 2007, the modified Laurie approach generates similar results to Laurie's. Crucially, and unlike the original approach, it calculates the cost of poverty in such a way that it is more likely to be sensitive to changes in widely recognized measures of poverty.

\section{$\underline{\text { Discussion }}$}

\section{Social assistance as investment}

In his estimates of the total cost of poverty, Laurie counts the cost of social assistance no less than twice. In the modified approach that we advance in this paper, we recommend not including it at all. On a technical level, adding the cost of social assistance to lost productivity is unnecessary if we measure it directly using earnings.

However, there is also a conceptual reason to exclude social assistance from social costs: it is a cost associated with investments we target to the poor in order to reduce the costs of poverty. In other words, these expenses should appear on the other side of our ledger. Theoretically, if governments invest adequately and wisely in social assistance, they should be able to entirely eliminate the costs of poverty, by eliminating the damage it can cause people and by ensuring that they have what they need to achieve the same economic opportunities as others. Over time, these measures could lead to the elimination of poverty altogether.

The exercise of calculating the costs of poverty is largely of value precisely because of how it helps us to think about the cost of social assistance differently: as an investment as opposed to a cost. It is all too common to think of social assistance strictly in terms of charitable

\footnotetext{
${ }^{22}$ This is automatically true for intergenerational health and crime costs because Laurie does not consider these at all. Our updates to remedial crime costs end up being greater because they are based on a much larger estimate of the total cost of crime.
} 
spending - costs governments incur in order to ensure a just and equitable society (Holzer et al. 2008). This, however, is only true up to a point - the cost of poverty, indicates where that point lies. In 2007, Canada invested less than $5-7 \%$ of the overall cost of poverty to social assistance, suggesting that it could spend as much as 14 times more on social assistance before its spending would be at risk of outpacing the potential savings it might incur.

Additionally, calculating the costs of poverty under multiple conditions and making comparison between them lets us not only underline the value of social investments but also think more constructively about how the transfers and services it includes can be improved. Some interventions are likely to reduce costs more than others. It is only by measuring and comparing costs that we can identify which these are with any amount of confidence.

Of course, there are still likely to remain many instances where social provisions can only be justified on the basis of justice or charity - for example, for individuals that suffer severe illness. At the very least, calculating the costs of poverty can provide us with a sign post for determining when this is the case and contrast these with instances where social investments can also be justified on economic grounds.

\section{Extending the approach}

The greatest limit to using the Laurie approach to inform and evaluate social policy is the paucity of quality and comparable research on the uneven association between income and health and crime outcomes. In order to be able to use cost of poverty estimates to gauge the efficiency of various policy interventions, either over time or among jurisdictions, our measures need to be sensitive to differences between places and times. Right now, via Statistics Canada's PUMF program, data is only reliably available to update productivity and government revenue at regular intervals.

This having been said, by working with existing administrative data sources, detailed and regularly updated estimates of the poverty related costs of both health and crime are well within our grasp. In the case of health research, the collection of the required data is already routine and the methods needed to relate them to costs have been well-established since at least the time of Mustard et. al's work in the 1990s. All that is needed for the purveyors of this data throughout the country to invest in routinely calculating and reporting on the association between income and health costs.

The study of income-related crime costs is less advanced but could be greatly informed by similar advances in health. For instance, it is common practice in health to link administrative data to income information in the Census using area-based measures. Though this results in an imperfect measure, it is not so imperfect that it has prevented health researchers from advancing several insights that are now being used to motivate more refined data linkages at the individual level (Hanley and Morgan 2008). In health fields, new screening tools that ask patients about their socio-economic characteristics are also being developed (for example, Brcic, Eberdt, and Kaczorowski 2011), which promise to provide a powerful supplement to administrative data (Jutte, Roos, and Brownell 2011).

Via Statistics Canada's PUMF program, the survey data needed to calculate opportunity costs and most intergenerational costs, at least down to the provincial level and extending back to the late 1970s, is already widely accessible through projects like the Data Liberation Initiative (DLI). The extension of the cost calculations is only limited by the coverage of this data, which excludes the Canadian territories, populations that are institutionalized, and those living on 
reserve or military bases. These populations are less likely to be overlooked in administrative taxfiler data that are now becoming increasingly available.

Finally, this study considers four areas of present costs but, data permitting, there are likely others that could also be considered. The presentation above makes clear what kinds of information that would be needed to be gathered by researchers about these new areas in order for them to be included.

\section{A bracketed approach}

The aim of this paper is to summarise and propose improvements to the Laurie approach to calculating the cost of poverty. This method is largely determined by the availability of data when Laurie created the method in the mid-aughts and by a desire to develop an approach that is relatively easy to understand and implement. However, in order to achieve these practical objectives, it makes a handful of conceptual concessions that may suggest directions for future approaches to explore.

The primary shortcoming of the Laurie approach, and also of the improved version presented in this paper, is that the limits of presently available information and data result in us having to determine average per person differences in outcomes between the poor and non-poor using the first and second income quintiles. Ideally, costs of poverty could be calculated by comparing the outcomes of similar people who are definitively known to only vary in terms of their being poor or non-poor. This kind of research program would depend on more refined measures of poverty and better income-linked health and crime data than is currently widely available.

Such an approach would also help to guard against another weakness in the approach: it is sensitive to changes in the outcomes of the second income quintile that may have little or nothing to do with the status of the poor. This is generally less of an issue if the outcomes of the second income quintile rise, but becomes an issue if they begin to deteriorate relative to the poor. For example, suppose that the health outcomes or literacy levels of households in the second income quintile were to deteriorate but not households at the bottom. Using Laurie's method, this would reduce the costs of poverty even though the poor would not be any better off. ${ }^{23}$

Relatedly, the approach implicitly assumes that there are no poor people in the second income quintile. This works in a context like Canada where, at least in the late 20th and early 21 st centuries, household poverty levels have tended to lay well below $20 \%$. This will not, however, work in a poorer country where poverty rates exceed $20 \%$. In these contexts, the Laurie method would in effect compare the poor to themselves in order to determine the costs of poverty. It also breaks down when we try to replicate the analysis for specific provinces, such as Newfound and Labrador, which have reported poverty levels in excess of $20 \%$ over the years.

Finally, the current design is also sensitive to government choices around spending. Theoretically, the costs of poverty could increase simply because a government decides to spend more on health or justice.

These limitations suggest that the Laurie approach is best recognized as a historically and contextually specific approach. By this we mean that it is unlikely to be an effective gauge in contexts that are too different from the present one. For example, in contexts where poverty

\footnotetext{
${ }^{23}$ Conversely, improving the costs associated with second and higher quintiles will also increase costs, although this is by design. The more opportunities a society provides its non-poor, the more costly it is to that society to leave people in poverty.
} 
levels are extremely low or high, where the outcomes of the top four quintiles are declining, and/or where levels of government spending are volatile.

\section{Conclusion}

In the late aughts, Nathan Laurie (2008) calculated the costs of poverty in Canada for the first time. In the years that have since followed, several Canadian researchers have worked with the method he developed to calculate the costs of poverty for most of the Canadian provinces. This body of research has had a substantial impact on public thinking about why we should address poverty in Canada and how much we can afford to commit to this endeavor.

In the early sections of this paper, we distill the central tenants of Laurie's approach. In effect, Laurie works with readily available data to answer the counterfactual question: what would the savings and gains to individuals and society be if we were to raise the standard of living of the poor in Canada to the modest level achieved by the second income quintile? He answers this question by estimating this difference in per person costs between the poor and non-poor and multiplying this by the number of people in society he identifies as poor.

Laurie is inconsistent in how he applies his own methodology across different areas of costs. In part, this is the result of the limits of the information and data that were available to him at the time he completed his research. However, in other instances, he could have done more to reconcile his calculations. A particularly pernicious oversight of the original Laurie methods is that it fails to be sensitive to changes in widely recognized measures of poverty.

In this paper, we propose several updates to the Laurie approach that draw on more recent sources of data and try to overcome some of the inconsistencies in Laurie's original calculations. In no particular order, they are:

- Differentiate costs within all categories of cost by quintile and contrast the first and second for remedial and opportunity costs.

- For intergenerational costs, contrast the discrepancy between the average of the top four quintiles and the second.

- Periodically update the cost shares used to calculate remedial costs and the mobility scaler used to calculate intergenerational costs.

- Periodically update total costs used to calculate remedial costs and adjust by inflation in between years.

- Use microdata to directly measure household earnings and taxes paid for calculating opportunity and intergenerational costs.

- If earnings are used to measure lost productivity, subtract lost government revenue from these when calculating total cost across all areas.

- If you wish to estimate lower and upper bounds on the costs of poverty, do so by varying the number of poor, not the stratifier (i.e. income quintile).

- Consider using the MBM and/or LIM rather than the LICO as the measure of poverty.

- As much as is possible, use a consistent definition of income quintile; ideally, adjusted after-tax income weighted at the household level.

- Do not include the cost of social assistance in calculations.

These recommendations will not result in an exact estimate of the cost of poverty. They will, however, result in estimates that are internally consistent and feasible to calculate using existing 
data. In line with the spirit of Laurie's original approach, they also tend to err on the side of underestimating the cost of poverty.

Ultimately, even this improved version of the Laurie approach suffers weaknesses. However, at the very least, the original Laurie approach and updated version proposed in this paper take us from having little to no knowledge of the costs of poverty to having a baseline understanding of it. They also help to clarify the steps we need to take to improve our understanding further.

\section{Appendix A: Why Laurie counts social assistance twice}

Laurie counts the total cost of social assistance in his cost of poverty calculations twice. In contrast, in the discussion section of this paper, we argue that we should not even count social assistance once. Laurie counts social assistance expenses the first time because he regards them a cost associated with poverty.

The second time, he does so because of his use of after-tax income as his indicator of productivity. In short, Laurie calculates the combined opportunity and social assistance costs of poverty $C_{O, S}$ as:

$$
C_{o, s}=A_{2}-A_{1}+T_{2}-T_{1}+2 S
$$

where $A_{1}$ and $A_{2}$ are average after-tax income in the first and second quintile respectively, $T_{1}$ and $T_{2}$, the average taxes paid by each quintile, and $S$ the total amount spent on social assistance.

Of course, after-tax income is actually a function of both $T_{j}$ and $S_{j}$, as well as earnings $E_{j}$, such that $A_{j}=E_{j}+S_{j}-T_{j}$. Substituting this into Equation A1 and simplifying, we get:

$$
\begin{aligned}
C_{o, s} & =A_{2}-A_{1}+T_{2}-T_{1}+2 S \\
& =E_{2}+S_{2}-T_{2}-\left(E_{1}+S_{1}-T_{1}\right)+T_{2}-T_{1}+2 S \\
& =E_{2}+S_{2}-T_{2}-E_{1}-S_{1}+T_{1}+T_{2}-T_{1}+2 S \\
& =E_{2}+S_{2}-E_{1}-S_{1}+2 S
\end{aligned}
$$

Assuming that the average costs of social assistance associated with the second quintile and higher are zero, $S_{1}=S, S_{2}=0$, and A2 can be simplified to:

$$
C_{o, s}=E_{2}-E_{1}+S_{1}
$$

In this paper, we argue we should measure productivity by using microdata to directly measure $E_{j}$ instead of trying to infer it from the combination of $A_{j}, T_{j}$, and $S_{j}$. Incidentally, this allows us to measure productivity without also measuring $S$. We also argue that it is misplaced to include the costs of social assistance in our cost of poverty calculations. 
Note that the above derivation also illustrates why $T$ should be subtracted from $E$ when productivity and government revenue costs are combined as is done in the calculations that we propose.

\section{$\underline{\text { References }}$}

Barayandema, Athanase, and Guy Frechet. 2012. The Cost of Poverty in Quebec According the the Model Proposed by Nathan Laurie. Quebec, QC: Centre d'étude sur la pauvreté et l'exclusion.

Bell, Alexander M., Raj Chetty, Xavier Jaravel, Neviana Petkova, and John Van Reenen. 2017. "Who Becomes an Inventor in America? The Importance of Exposure to Innovation."

Brady, David. 2003. "Rethinking the Sociological Measurement of Poverty." Social Forces 81(3):715-51.

Brcic, Vanessa, Caroline Eberdt, and Janusz Kaczorowski. 2011. "Development of a Tool to Identify Poverty in a Family Practice Setting: A Pilot Study." International Journal of Family Medicine 2011:812182.

Briggs, Alexa, and Celia Lee. 2012. Poverty Costs: An Economic Case for a Preventative Poverty Reduction Strategy in Alberta. Calgary, AB: Vibrant Communities Calgary and Action to End Poverty in Alberta.

CIHI. 2015. Trends in Income-Related Health Inequalities in Canada: Summary Report. Vol. 18. Canadian Institute for Health Information.

CIHI. 2018a. National Health Expenditure Trends, 1975 to 2018. Canadian Institute for Health Information.

CIHI. 2018b. National Health Expenditure Trends, 1975 to 2018: Methodology Notes. Canadian Institute for Health Information.

Corak, Miles. 2013. "Income Inequality, Equality of Opportunity, and Intergenerational Mobility." The Journal of Economic Perspectives: A Journal of the American Economic Association 27(3):79-102.

Corak, Miles. 2017. Divided Landscapes of Economic Opportunity: The Canadian Geography of Intergenerational Income Mobility. 2017-043. Human Capital and Economic Opportunity Working Group.

Duflo, Esther. 2006. "Poor but Rational?" in Understanding Poverty. New York: Oxford University Press.

Eisler, Lauren, and Bernard Schissel. 2004. "Privation and Vulnerability to Victimization for Canadian Youth: The Contexts of Gender, Race, and Geography." Youth Violence and Juvenile Justice 2(4):359-73.

Fortin and Sophie, Nicole. 1998. "Intergenerational Income Mobility In Canada." Pp. 51-64 in Labour Markets, Social Institutions, and the Future of Canada's Children, edited by M. Corak. Ottawa: Statistics Canada.

Gaetz, Stephen. 2004. "Safe Streets for Whom? Homeless Youth, Social Exclusion, and Criminal Victimization." Canadian Journal of Criminology and Criminal Justice 46(4):423-56.

Gannon, Maire, Karen Mihorean, Karen Beattie, Andrea Taylor-Butts, and Rebecca Kong. 2005. Criminal Justice Indicators. Statistics Canada.

GoC. 2018. Opportunity for All: Canada's First Poverty Reduction Strategy. Government of Canada. 
Green, David A., and Craig W. Riddell. 2007. Literacy and the Labour Market: The Generation of Literacy and Its Impact on Earnings for Native Born Canadians. Statistics Canada.

Hanley, Gillian E., and Steve Morgan. 2008. "On the Validity of Area-Based Income Measures to Proxy Household Income.” BMC Health Services Research 8:79.

Haushofer, Johannes, and Ernst Fehr. 2014. "On the Psychology of Poverty." Science 344(6186):862-67.

Hirsch, Donald. 2008. Estimating the Costs of Child Poverty. The Joseph Rowntree Foundation.

Holzer, Harry J., Diane Whitmore Schanzenbach, Greg J. Duncan, and Jens Ludwig. 2008. "The Economic Costs of Childhood Poverty in the United States." Journal of Children and Poverty 14(1):41-61.

Hou, Feng, and John Myles. 2008. "The Changing Role of Education in the Marriage Market: Assortative Marriage in Canada and the United States since the 1970s." Canadian Journal of Sociology = Cahiers Canadiens de Sociologie 33(2).

Hsieh, Ching-Chi, and M. D. Pugh. 1993. "Poverty, Income Inequality, and Violent Crime: A Meta-Analysis of Recent Aggregate Data Studies." Criminal Justice Review 18(2):182-202.

Hunter, Garson, and Dionne Miazdyck. 2006. "Current Issues Surrounding Poverty and Welfare Programming in Canada." Pp. 383-418 in Social Fabric Or Patchwork Quilt: The Development of Social Policy in Canada, edited by R. Blake and J. Keshen. Peterborough, Ontario: Broadview Press.

IMF. 2001. Government Finance Statistics Manual 2001 (GFSM 2001). Washington, D.C: International Monetary Fund.

Ivanova, Iglika. 2011. The Cost of Poverty in BC. Vancouver BC: Canadian Centre for Policy Alternatives.

Jutte, Douglas P., Leslie L. Roos, and Marni D. Brownell. 2011. "Administrative Record Linkage as a Tool for Public Health Research." Annual Review of Public Health 32:91-108.

Laurie, Nathan. 2008. The Cost of Poverty: An Analysis of the Economic Cost of Poverty in Ontario. Ontario Association of Food Banks.

Lee, Celia, and Alexa Briggs. 2019. The Cost of Poverty in Ontario: 10 Years Later. Feed Ontario.

Leung, Ambrose. 2004. The Cost of Pain Suffering from Crime in Canada. Department of Justice Canada.

Lutfey, Karen, and Jeremy Freese. 2005. "Toward Some Fundamentals of Fundamental Causality: Socioeconomic Status and Health in the Routine Clinic Visit for Diabetes." The American Journal of Sociology 110(5):1326-72.

MacEwen, Angella. 2011. Cost of Poverty in Prince Edward Island. Canadian Centre for Policy Alternatives.

MacEwen, Angella, and Christine Saulnier. 2010. Cost of Poverty in Nova Scotia. Halifax, NS: Canadian Centre for Policy Alternatives.

MacEwen, Angella, and Christine Saulnier. 2011. Cost of Poverty in New Brunswick. Halifax, NS: Canadian Centre for Policy Alternatives.

Mani, Anandi, Sendhil Mullainathan, Eldar Shafir, and Jiaying Zhao. 2013. "Poverty Impedes Cognitive Function.” Science 341(6149):976-80.

McLaughlin, Michael, and Mark R. Rank. 2018. "Estimating the Economic Cost of Childhood Poverty in the United States." Social Work Research 42(2):73-83.

Muirhead, James E., and Robert Rhodes. 1998. "Literacy Level of Canadian Federal Offenders." 
Journal of Correctional Education 49(2):59-60.

Murphy, Brian B., Xuelin Zhang, and Claude Dionne. 2012. Low Income in Canada: A Multi-Line and Multi-Index Perspective. 1100198954. Ottawa, Ontario: Statistics Canada.

Murphy, Brian, Xuelin Zhang, and Claude Dion. 2010. Revising Statistics Canada's Low Income Measure (LIM). 75F0002M - No. 004. Statistics Canada, Income Statistics Division.

Mustard, Cameron A., Morris Barer, Robert G. Evans, John Horne, Teresa Mayer, and Shelley Derksen. 1998. "Paying Taxes and Using Health Services: The Distributional Consequences of Tax Financed Universal Health Insurance in a Canadian Province." in Conference on the State of Living Standards and the Quality of Life in Canada. Ottawa, ON.

PHAC. 2016. The Direct Economic Burden of Socio-Economic Health Inequalities In Canada. Public Health Agency of Canada.

PHAC. 2018. Key Health Inequalities in Canada: A National Portrait. Public Health Agency of Canada.

Plante, Charles, Sharalynn Missiuna, and Cory Neudorf. 2020. Urban Income-Related Health Inequalities in Canada: City-Level Results in Health System Use and Self-Reported Indicators. Urban Public Health Network.

Plante, Charles, and Keisha Sharp. 2014. Poverty Costs Saskatchewan: A New Approach to Prosperity for All. Poverty Costs.

Statistics Canada. 2014. Overview of the Canadian Government Finance Statistics. Statistics Canada.

Statistics Canada. 2016. Low Income Lines: What They Are and How They Are Created? Statistics Canada.

Taylor-Butts, Andrea. 2002. Justice Spending in Canada, 2000/01. Statistics Canada.

Taylor-Butts, Andrea. 2009. Household Income and Victimization in Canada, 2004. Statistics Canada.

Zhang, Ting. 2010. Costs of Crime in Canada, 2008. Department of Justice Canada. 


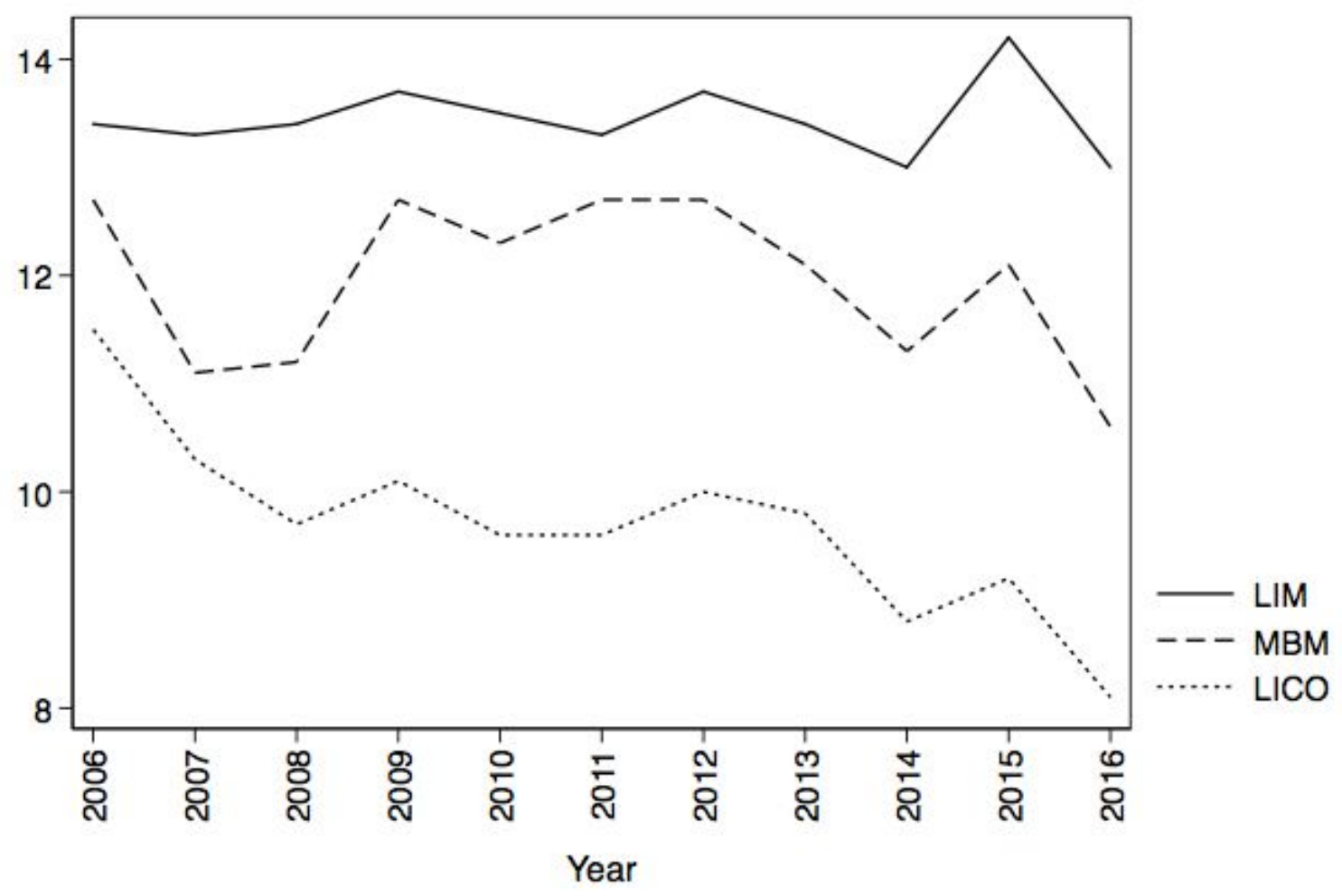

Figure 1. Recent trends Canada poverty rate according to leading Canadian low-income measures (Source: SLID and CIS) 


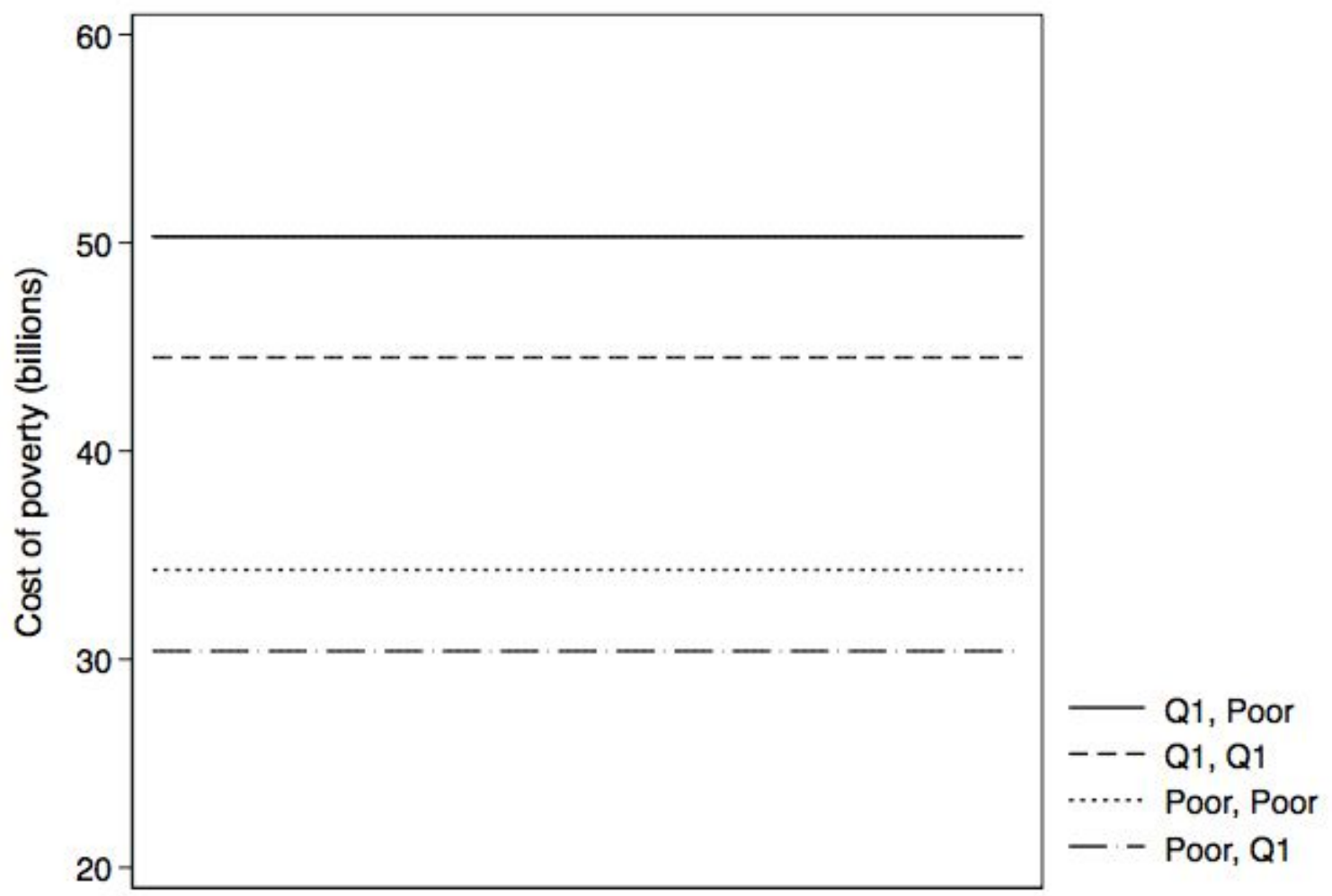

Figure 2. Opportunity cost of poverty estimates based on different combinations of using households in the bottom quintile or below the MBM to calculate $P$ and $\bar{Z}$ (Source: PUMF-SLID 2007) 


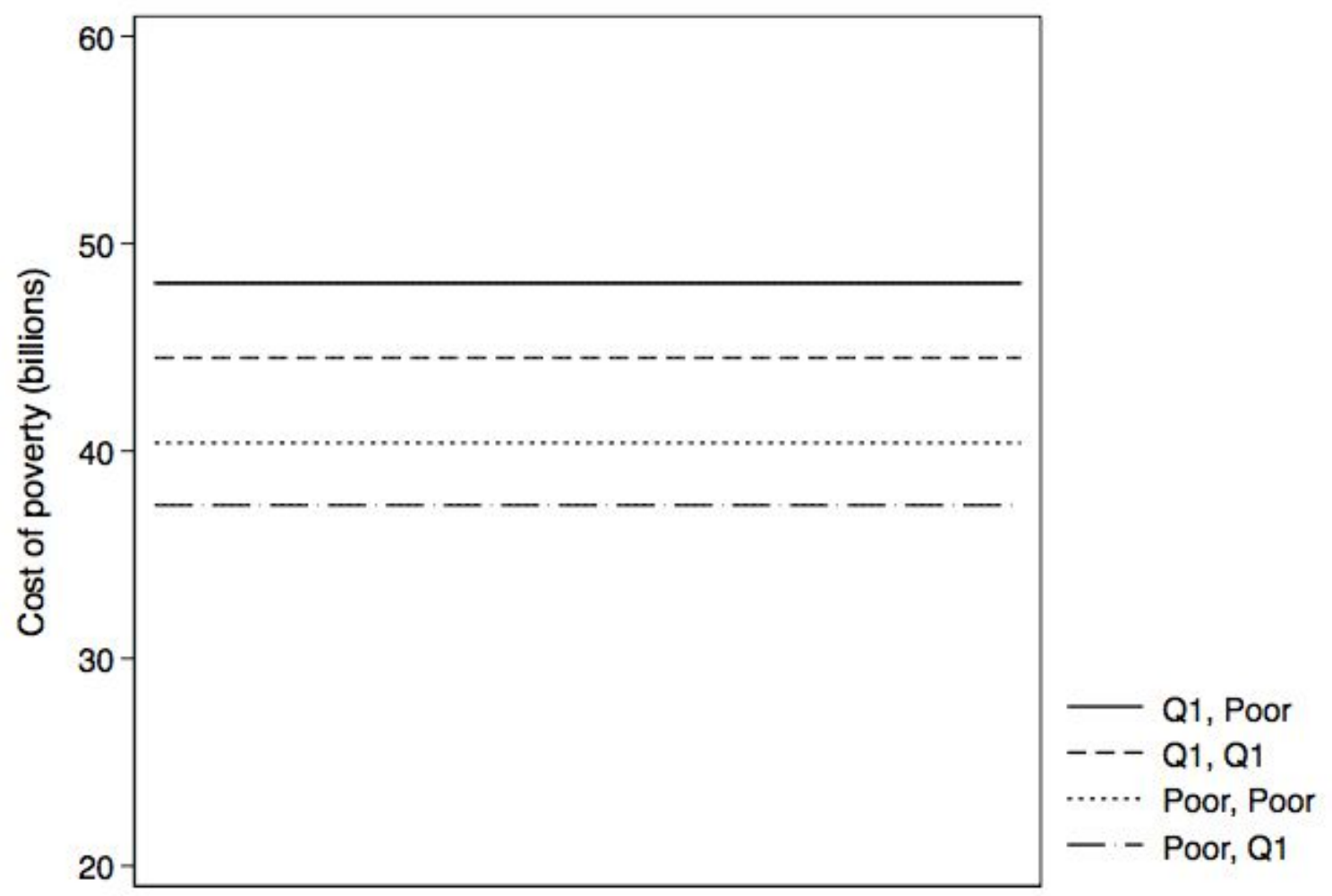

Figure 3. Opportunity cost of poverty estimates based on different combinations of using households in the bottom quintile or below the LIM to calculate $P$ and $\bar{Z}$ (Source: PUMF-SLID 2007) 
Table 1. Typical features of non-elderly and elderly households in the second adjusted after-tax income quintile

\begin{tabular}{lccccc}
\hline & \multicolumn{2}{c}{ Non-elderly } & & \multicolumn{2}{c}{ Elderly } \\
\cline { 2 - 3 } \cline { 5 - 6 } Variable & Mean & SE & & Mean & SE \\
\hline Number of chidlren & 0.7 & 0.025 & & 0.1 & 0.011 \\
Number of adults & 2.0 & 0.023 & & 0.3 & 0.023 \\
Number of elderly & 0.0 & -- & & 1.4 & 0.014 \\
Household size & 2.7 & & & & \\
Earnings & $\$ 32,242$ & 405.739 & & $\$ 3,064$ & 269.412 \\
Total income & $\$ 42,214$ & 318.983 & & $\$ 32,230$ & 286.550 \\
After-tax income & $\$ 38,614$ & 291.933 & & $\$ 31,073$ & 268.983 \\
Taxes paid & $\$ 3,601$ & 67.161 & & $\$ 1,157$ & 72.022 \\
Poverty rate (MBM) & $0.91 \%$ & 0.002 & & $0.66 \%$ & 0.002 \\
Poverty rate (LIM) & $0.00 \%$ & -- & $0.00 \%$ & -- \\
\hline
\end{tabular}

Note: Non-elderly households are households with no members 65 years of age or older and elderly households contain at least one elderly member; adults are individuals between 26 and 64 years old. 
Table 2. Cost of poverty of in Canada using Laurie's approach, implicit and explicit values.

\begin{tabular}{|c|c|c|c|c|c|}
\hline Present costs & $P$ & Unit & $Z$-bar & $X$-bar & Total cost (billions) \\
\hline Health & $2,630,100$ & households & $-\$ 13,276$ & $-\$ 10,397$ & $\$ 7.6$ \\
\hline Crime & $2,630,100$ & households & $-\$ 2,537$ to $-\$ 5,468$ & $-\$ 2,210$ to $-\$ 4,763$ & $\$ 0.9$ to $\$ 1.9$ \\
\hline Lost productivity & $1,948,850$ & households & $\$ 16,000$ to $\$ 18,765$ & $\$ 37,154$ & $\$ 35.8$ to $\$ 41.2$ \\
\hline Lost revenue & $1,948,850$ & households & $\$ 800$ to $\$ 1,495$ & $\$ 5,894$ & $\$ 8.6$ to $\$ 9.9$ \\
\hline Social assistance & $2,630,100$ & households & $-\$ 3,118$ & $\$ 0$ & $\$ 8.2$ \\
\hline Total & & & & & $\$ 61.0$ to $\$ 68.8$ \\
\hline Life course costs & $P$ & Unit & $Z$-bar & $X$-bar & Total cost \\
\hline Health & -- & -- & -- & -- & -- \\
\hline Crime & -- & -- & -- & -- & -- \\
\hline Lost productivity & 152,000 to 190,000 & children & $\$ 16,000$ & $\$ 70,050$ & $\$ 8.2$ to $\$ 10.3$ \\
\hline Lost revenue & 152,000 to 190,000 & children & $\$ 800$ & $\$ 19,308$ & $\$ 2.8$ to $\$ 3.5$ \\
\hline Total & & & & & $\$ 11.0$ to $\$ 13.8$ \\
\hline Combined total & & & & & $\$ 72.1$ to $\$ 82.6$ \\
\hline
\end{tabular}

Note: All totals are recalculated based on methods and quantities reported in Laurie (2008). Mistakes in how he calculated present lost revenue and life course lost revenue have been corrected. 
Table 3. Health care expenditure shares by income quintiles, old and new estimates

\begin{tabular}{ccccc}
\hline & \multicolumn{2}{c}{ Mustard et al. (1998) } & & \multicolumn{2}{c}{ PHAC (2016) } \\
\cline { 2 - 3 } Income & Shares & & Amount (millions) & Shares \\
\hline Q1 & 0.309 & & $\$ 11,248$ & 0.257 \\
Q2 & 0.242 & & $\$ 8,759$ & 0.200 \\
Q3 & 0.162 & $\$ 8,222$ & 0.188 \\
Q4 & 0.141 & $\$ 8,057$ & 0.184 \\
Q5 & 0.146 & $\$ 7,520$ & 0.172 \\
\hline Total & 1.000 & $\$ 43,807$ & 1.000
\end{tabular}

Note: Mustard et al. (1998) actually tabulate costs by decile; Laurie (2008) combined these to create his quintile estimates. 
Table 4. Breakdown of public-sector health expenditure by use of funds in 2007 (CIHI 2017)

\begin{tabular}{lcc}
\hline Use of funds & Amount (millions) & Percent \\
\hline Hospitals & 42,377 & $37.7 \%$ \\
Other institutions & 12,192 & $10.8 \%$ \\
Physicians & 21,309 & $19.0 \%$ \\
Other professionals: Dental services & 542 & $0.5 \%$ \\
Other professionals: Vision care services & 240 & $0.2 \%$ \\
Other professionals: Other services & 542 & $0.5 \%$ \\
Prescribed drugs & 10,144 & $9.0 \%$ \\
Capital & 5,705 & $5.1 \%$ \\
Public health & 9,055 & $8.1 \%$ \\
Administration & 2,549 & $2.3 \%$ \\
Other health spending: Health research & 1,918 & $1.7 \%$ \\
Other health spending: Other & 5,800 & $5.2 \%$ \\
\hline Total & 112,372 & $100.0 \%$ \\
\hline Notes: "Other instutitions" includes residential care types of facilities that are funded by \\
government health and/or social services and "Other services" includes things like \\
chiropractors, osteopaths, physiotherapists, psychologists, and nurses (CIHII 2017).
\end{tabular}


Table 5a. Distribution of income quintile conditional on literacy quintile.

\begin{tabular}{cccccc}
\hline & \multicolumn{5}{c}{ Literacy } \\
\cline { 2 - 6 } Income & Q1 & Q2 & Q3 & Q4 & Q5 \\
\hline Q1 & 0.417 & 0.221 & 0.124 & 0.095 & 0.064 \\
Q2 & 0.291 & 0.266 & 0.194 & 0.159 & 0.119 \\
Q3 & 0.171 & 0.221 & 0.239 & 0.219 & 0.208 \\
Q4 & 0.080 & 0.171 & 0.244 & 0.259 & 0.243 \\
Q5 & 0.040 & 0.121 & 0.199 & 0.269 & 0.366 \\
\hline Total & 1.000 & 1.000 & 1.000 & 1.000 & 1.000 \\
\hline
\end{tabular}

Note: This table is derrived from the joint distribution of income and literacy quintiles in Green and Ridell (2007:13).

Table 5b. Distribution of probability of engaging in crime conditional on literacy quintile.

\begin{tabular}{cccccccc}
\hline & \multicolumn{5}{c}{ Literacy } & Q5 & Total \\
\cline { 2 - 7 } & $\mathrm{Q} 1$ & $\mathrm{Q} 2$ & $\mathrm{Q} 3$ & 0.065 & 0.032 & 1.000 \\
\hline Crime & 0.516 & 0.258 & 0.129 & 0 & 0 \\
\hline
\end{tabular}

Note: These numbers are taken from Barayandema and Fréchet (2012:10) as Laurie (2008) does not provide them explicitly. In an appendix, Barayandema and Fréchet explain how they are calculated.

Table 5c. Distribution of probability of engaging in crime conditional on income and literacy quintiles.

\begin{tabular}{ccccccc}
\hline & \multicolumn{5}{c}{ Literacy } & $\begin{array}{c}\text { Probability of } \\
\text { Engaging in Crime }\end{array}$ \\
\cline { 2 - 6 } Income & Q1 & Q2 & Q3 & Q4 & Q5 & 0.297 \\
Q2 & 0.215 & 0.057 & 0.016 & 0.006 & 0.002 & 0.258 \\
Q3 & 0.150 & 0.069 & 0.025 & 0.010 & 0.004 & 0.197 \\
Q4 & 0.088 & 0.057 & 0.031 & 0.014 & 0.007 & 0.142 \\
Q5 & 0.041 & 0.044 & 0.031 & 0.017 & 0.008 & 0.107 \\
\hline Total & 0.021 & 0.031 & 0.026 & 0.017 & 0.012 & 1.000 \\
\hline
\end{tabular}

Note: Each column in the inner part of this table is the product of the same column in Tables $5 \mathrm{a}$ and $5 \mathrm{~b}$; the rightmost column, then, which presents the sum of each row, is also the product of Table 5a and the transpose of Table 5b. 
Table 6. Total tangible and intantible costs of crime according to Zhang (2010) (billions).

\begin{tabular}{lccc}
\hline Costs of crime & Laurie (2008) & Zhang (2010) & Without conflicts \\
\hline $\begin{array}{l}\text { Tangible costs } \\
\text { Criminal justice system }\end{array}$ & $\$ 13$ & $\$ 14.6$ & $\$ 14.6$ \\
$\quad$ To victims & $\$ 9.8$ to $\$ 35.8$ & $\$ 13.9$ & $\$ 6.0$ \\
$\quad \begin{array}{l}\text { To third-parties } \\
\text { Intangible }\end{array}$ & -- & $\$ 2.0$ & $\$ 0.9$ \\
$\quad$ Pain and suffering & -- & $\$ 63.1$ & $\$ 63.1$ \\
$\quad$ Loss of life & -- & $\$ 3.0$ & $\$ 3.0$ \\
\hline Total & $\$ 22.5$ to $\$ 48.5$ & $\$ 93.7$ & $\$ 84.9$ \\
\hline $\begin{array}{l}\text { Note: Laurie does not adjust his costs estimates for inflation-his justice system costs are cast in 2003 } \\
\text { dollars and his victims costs in 1999 dollars. I have adjusted Zhang's cost estimates to reflect 2007 dollars. }\end{array}$
\end{tabular}


Table 7. Esitmates of average non-edlerly household income and taxes paid by income quintile used by Laurie and new calculated using PUMF-SLID

\begin{tabular}{|c|c|c|c|c|c|}
\hline \multirow[b]{2}{*}{ Income } & \multicolumn{3}{|c|}{ Laurie (2008) } & \multicolumn{2}{|c|}{2007 PUMF-SLID } \\
\hline & Before-tax income & After-tax income & Taxes paid, inferred & Earnings & Taxes paid, actua \\
\hline Poor (LICO) & $\$ 16,800$ & $\$ 16,000$ & $\$ 800$ & $\$ 5,572$ & $\$ 495$ \\
\hline Q1 & $\$ 20,260$ & $\$ 18,765$ & $\$ 1,495$ & $\$ 8,752$ & $\$ 627$ \\
\hline Q2 & $\$ 43,048$ & $\$ 37,154$ & $\$ 5,894$ & $\$ 29,735$ & $\$ 3,368$ \\
\hline Q3 & $\$ 64,785$ & $\$ 53,138$ & $\$ 11,627$ & $\$ 49,424$ & $\$ 7,844$ \\
\hline Q4 & $\$ 89,268$ & $\$ 71,413$ & $\$ 17,855$ & $\$ 74,716$ & $\$ 14,044$ \\
\hline Q5 & $\$ 160,352$ & $\$ 118,495$ & $\$ 41,857$ & $\$ 142,435$ & $\$ 36,298$ \\
\hline Q2 - Poor (LICO) & & $\$ 21,154$ & $\$ 5,094$ & $\$ 24,163$ & $\$ 2,873$ \\
\hline Q2 - Q1 & & $\$ 18,389$ & $\$ 4,399$ & $\$ 20,983$ & $\$ 2,741$ \\
\hline
\end{tabular}

Note: Laurie's estimates were special ordered from Statistics Canada for 2006 and where not adjusted for inflation. My estimates were calculated using the PUMF-SLID 2007 and are expressed in nominal dollars in that year. 
Table 8. Probabilities that chidlren from various income quintiles will end up in the same quintile as their parents

\begin{tabular}{cccccc}
\hline \multirow{2}{*}{$\begin{array}{c}\text { Income in } \\
\text { childhood }\end{array}$} & Q1 & Q2 & Q3 & Q4 & Q5 \\
\cline { 2 - 6 } Q1 & 0.301 & 0.239 & 0.191 & 0.155 & 0.114 \\
Q2 & 0.217 & 0.234 & 0.214 & 0.189 & 0.146 \\
Q3 & 0.177 & 0.201 & 0.219 & 0.215 & 0.188 \\
Q4 & 0.154 & 0.173 & 0.203 & 0.229 & 0.241 \\
Q5 & 0.137 & 0.145 & 0.175 & 0.22 & 0.323 \\
\hline
\end{tabular}

Note: Theses estimates were calculated by Corak (2017). 
Table 9. Cost of lost productivity using different combinations of $\mathrm{P}$ and Z-bar based on first quintile and/or poor according to the MBM

\begin{tabular}{lcccc}
\hline Combination & P & Z-bar & X-bar & Y (billions) \\
\hline Poor, Q1 & $1,447,463$ & $\$ 8,752$ & $\$ 29,735$ & $\$ 30.4$ \\
Poor, Poor & $1,447,463$ & $\$ 6,028$ & $\$ 29,735$ & $\$ 34.3$ \\
Q1, Q1 & $2,120,305$ & $\$ 8,752$ & $\$ 29,735$ & $\$ 44.5$ \\
Q1, Poor & $2,120,305$ & $\$ 6,028$ & $\$ 29,735$ & $\$ 50.3$ \\
\hline
\end{tabular}

Notes: In this table, I use the MBM to define poverty; although Laurie uses the LICO, this measure has now largely fallen out of use. 
Table 10. Cost of poverty of in Canada using new recommended approach based on different measures of poverty.

\begin{tabular}{|c|c|c|c|c|c|c|}
\hline \multirow[b]{3}{*}{ Present costs } & \multirow[b]{3}{*}{ Unit } & \multirow[b]{3}{*}{ Z-bar } & \multirow[b]{3}{*}{ X-bar } & \multicolumn{3}{|c|}{ Totals using various poverty measures for $\mathrm{P}$ (billions) } \\
\hline & & & & $\begin{array}{c}\mathrm{MBM} \\
(\mathrm{P}=1,526,387)\end{array}$ & $\begin{array}{c}\text { LIM } \\
(\mathrm{P}=2,103,589)\end{array}$ & $\begin{array}{c}\text { Quintile } \\
(\mathrm{P}=2,630,100)\end{array}$ \\
\hline & & & & $(\mathrm{Q}=1,447,463)$ & $(\mathrm{Q}=1,781,984)$ & $(\mathrm{Q}=2,120,305)$ \\
\hline Health & households & $-\$ 11,032$ & $-\$ 8,591$ & $\$ 3.7$ & $\$ 5.1$ & $\$ 6.4$ \\
\hline Crime & households & $-\$ 9,574$ & $-\$ 8,339$ & $\$ 1.9$ & $\$ 2.6$ & $\$ 3.2$ \\
\hline Lost productivity & households & $\$ 8,752$ & $\$ 29,735$ & $\$ 30.4$ & $\$ 37.4$ & $\$ 44.5$ \\
\hline Lost revenue & households & $\$ 627$ & $\$ 3,368$ & $\$ 4.0$ & $\$ 4.9$ & $\$ 5.8$ \\
\hline Total & & & & $\$ 36.0$ & $\$ 45.1$ & $\$ 54.2$ \\
\hline Life course costs & Unit & X-bar & V-bar & $(\mathrm{R}=215,849)$ & $(\mathrm{R}=279,130)$ & $(\mathrm{R}=349,607)$ \\
\hline Health & children & $-\$ 8,591$ & $-\$ 7,983$ & $\$ 0.1$ & $\$ 0.2$ & $\$ 0.2$ \\
\hline Crime & children & $-\$ 8,339$ & $-\$ 5,679$ & $\$ 0.6$ & $\$ 0.7$ & $\$ 0.9$ \\
\hline Lost productivity & children & $\$ 29,735$ & $\$ 77,031$ & $\$ 10.2$ & $\$ 13.2$ & $\$ 16.5$ \\
\hline Lost revenue & children & $\$ 3,368$ & $\$ 16,233$ & $\$ 2.8$ & $\$ 3.6$ & $\$ 4.5$ \\
\hline Total & & & & $\$ 10.9$ & $\$ 14.1$ & $\$ 17.7$ \\
\hline Combined total & & & & $\$ 46.9$ & $\$ 59.2$ & $\$ 71.8$ \\
\hline
\end{tabular}

Note: Totals exclude lost revenue costs as these costs are already included in lost productivity costs. 